\title{
Dosimetric Evaluation of Tumor Tracking in 4D Radiotherapy
}

\author{
I. Buzurovic \\ Thomas Jefferson University Hospitals \\ M. Werner-Wasik \\ Thomas Jefferson University Hospitals \\ T. Biswas \\ Thomas Jefferson University Hospitals \\ J. Galvin \\ Thomas Jefferson University Hospitals
}

A. Dicker

Thomas Jefferson University Hospitals

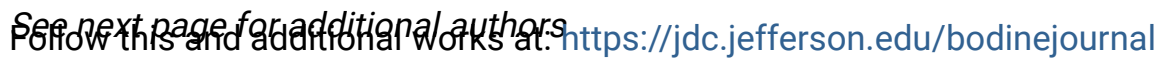 \\ Part of the Oncology Commons \\ Let us know how access to this document benefits you}

\section{Recommended Citation}

Buzurovic, I.; Werner-Wasik, M.; Biswas, T.; Galvin, J.; Dicker, A.; Yu, Y.; and Podder, T. (2010) "Dosimetric Evaluation of Tumor Tracking in 4D Radiotherapy," Bodine Journal: Vol. 3 : Iss. 1 , Article 24.

DOI: https://doi.org/10.29046/TBJ.003.1.023

Available at: https://jdc.jefferson.edu/bodinejournal/vol3/iss1/24

This Article is brought to you for free and open access by the Jefferson Digital Commons. The Jefferson Digital Commons is a service of Thomas Jefferson University's Center for Teaching and Learning (CTL). The Commons is a showcase for Jefferson books and journals, peer-reviewed scholarly publications, unique historical collections from the University archives, and teaching tools. The Jefferson Digital Commons allows researchers and interested readers anywhere in the world to learn about and keep up to date with Jefferson scholarship. This article has been accepted for inclusion in Bodine Journal by an authorized administrator of the Jefferson Digital Commons. For more information, please contact: JeffersonDigitalCommons@jefferson.edu. 
Dosimetric Evaluation of Tumor Tracking in 4D Radiotherapy

Authors

I. Buzurovic, M. Werner-Wasik, T. Biswas, J. Galvin, A. Dicker, Y. Yu, and T. Podder 


\title{
Dosimetric Evaluation of Tumor Tracking in 4D Radiotherapy
}

\author{
Buzurovic, I., Werner-Wasik, M., Biswas, T., Galvin, J., Dicker, A., Yu, Y., Podder, T. \\ Department of Radiation Oncology, Thomas Jefferson University Hospitals, Philadelphia, PA
}

\section{Purpose}

In some patients the tumors in lung, pancreas, liver, breast, and other organs move significantly during cardiac and breathing cycles. In this study we have investigated the dosimetric benefits of real-time tumor tracking for patients who were diagnosed with lung cancer.

\section{Materials and Methods}

The study includes the evaluation of dosimetric advantages of tumor motion tracking and the irradiation of normal lung and spinal cord. The dosimetric evaluation of tumor tracking was carried out on ten randomly selected patients who were scanned using $4 \mathrm{D}$-CT technique. The $4 \mathrm{D}$-CT phase reconstruction was performed using GE Advantage Workstation software, version AW 4.3_07. The 3D-CRT plans were generated using CMS-XiO4.4. Tissue heterogeneity was corrected for all plans. For each patient, eleven dosimetric plans were generated: ten plans for the target volumes contoured at ten breathing phases and one plan for the internal target volume (ITV) generated on average intensity projection (AvIP) studyset. The ITV was defined as a spatial sum of the gross target volumes (GTV) for each phase. The phasewise plans were compared to the clinically used ITV-AvIP plans in order to assess dosimetric effects of tumor tracking. The planning target volumes (PTV) were generated by adding $10 \mathrm{~mm}$ margin around GTVs and ITV for both phase-wise plans and ITVAvIP plans. To analyze data obtained from the dosimetric plans we compared dosimetric parameters including coverage of PTV (D99, D95, D50) volumes of normal lung receiving 5Gy, 13Gy, 20Gy, 30Gy dose (V5, V13, V20, V30) and D5 of spinal cord for AvIP-based plans with phase-wise tracked plans.

\section{Results}

Average PTV coverages for all plans were $91.6 \%$ of the prescribed dose (PD) for D99, 96.7\% for D95 and $104.3 \%$ for D50. The average maximum dose was $110 \%$ of $\mathrm{PD}$ and the mean dose was $103.6 \%$ of $\mathrm{PD}$. The 3D tumor motions for all investigated patients were more than $10 \mathrm{~mm}$. It was observed that average V5, V13, V20 and V30 with tracking technique were about $17.4 \%, 19.3 \%, 18.3 \%$ and $22.7 \%$ lower than the Vxs without tracking, respectively. Approximately $20 \%$ of healthy lung received $4-8 \mathrm{~Gy}$ less dose when the tumor tracking technique was used. Spinal cord was the most important critical organ for the studied lung cases. Dose to the spinal cord (D5) with tracking technique was $17.5 \%$ lower compared to that of without tracking. D5 of the spinal cord received approximately 0.5-11 Gy less dose when tumor tracking technique was used; wide variations were observed due to differences in prescribed dose, tumor location and size.

\section{Conclusion}

Implementation of the active tracking and dynamic dose delivery techniques can potentially improve dose distribution of the tumorvolumes. This, in turn, will potentially improve the quality of patient treatment by minimizing irradiation to the healthy tissues, sparing critical organs and lowering the toxicities. 